\title{
Interaction between the physical form of the starter feed and straw provision on growth performance of Holstein calves
}

\author{
M. Terré, ${ }^{*}$ LI. Castells, ${ }^{*}$ M. A. Khan, $\dagger$ and A. Bach ${ }^{*} \ddagger^{1}$ \\ *Department of Ruminant Production, IRTA (Institut de Recerca i Tecnologia Agroalimentàries), 08140 Caldes de Montbui, Spain \\ †Animal Welfare Program, University of British Columbia, 2357 Mall, Vancouver, BC, Canada V6T 1 Z4 \\ †ICREA (Institució Catalana de Recerca i Estudis Avançats), 08010 Barcelona, Spain
}

\section{ABSTRACT}

Two experiments were conducted to assess the effect of physical form of a starter feed with or without straw supplementation on growth performance of Holstein calves. In experiment 1, a total of 32 calves were randomly assigned at $7 \mathrm{~d}$ of age to texturized starter feed (containing rolled barley, corn, and oats) without straw, texturized starter feed with chopped straw, and pelleted starter feed with chopped straw. All calves were offered $4 \mathrm{~L}$ of pasteurized whole milk twice daily from 7 to $35 \mathrm{~d}$ of age, $2 \mathrm{~L}$ of milk twice daily from 36 to $42 \mathrm{~d}$ of age, and $2 \mathrm{~L}$ of milk from 43 to $49 \mathrm{~d}$ of age. Animals were weaned at $50 \mathrm{~d}$ of age, and the study finished when calves were $63 \mathrm{~d}$ old. In experiment 2 , a total of 60 calves ( $8 \mathrm{~d}$ of age) were randomly assigned to texturized starter feed (containing whole corn) without straw, pelleted starter feed without straw, and pelleted starter feed with chopped straw. All calves were offered the same milk replacer (MR; $23 \%$ crude protein and 19.5 fat) at $11 \%$ dry matter concentration, $4 \mathrm{~L} / \mathrm{d}$ of MR until $14 \mathrm{~d}$ of age, $6 \mathrm{~L} / \mathrm{d}$ of MR from 14 to $37 \mathrm{~d}, 3 \mathrm{~L} / \mathrm{d}$ of MR from 38 to $44 \mathrm{~d}$, and $1.5 \mathrm{~L} / \mathrm{d}$ of MR from 45 to $52 \mathrm{~d}$ of age. The experiment finished when calves were $58 \mathrm{~d}$ old (1 wk after weaning). Rumen liquid $\mathrm{pH}$ was measured after weaning. In both studies, calves were individually housed in pens on sawdust bedding and starter feed and chopped straw were offered free choice in separate buckets. In experiment 1 , starter feed and straw intake and growth did not differ among treatments. However, calves receiving straw showed a greater rumen $\mathrm{pH}$ compared with those not receiving straw. In experiment 2 , pelleted started feed supplemented with straw fostered an increase in solid feed intake (as percentage of body weight) compared with a pelleted or texturized starter feed without straw supplementation. However, calves that received the texturized starter feed containing whole corn had rumen $\mathrm{pH}$ similar to

Received March 20, 2014.

Accepted November 4, 2014.

${ }^{1}$ Corresponding author: alex.bach@icrea.cat those fed a pelleted starter feed with straw. Feeding a texturized starter feed containing rolled barley, corn, and oats (with or without straw provision) was not able to maintain rumen $\mathrm{pH}$ or promote growth and intake compared with offering a pelleted starter feed with chopped straw. However, when whole corn was used in the texturized starter feed, rumen $\mathrm{pH}$ was equivalent to that obtained with a pelleted starter feed and straw supplementation.

Key words: calf, forage, texturized starter feed, straw

\section{INTRODUCTION}

Early weaning and restricted-milk feeding programs have been widely used as strategies to reduce feeding cost of rearing young calves and encourage starter feed consumption in dairy calves. However, research during the last decade has shown advantages of providing more milk or milk replacer on improving calf growth, welfare, and future productivity, which requires reevaluation of the effects of solid feeds (starter feed and forage) on the performance of developing calves (Khan et al., 2011a). Feeding forage to calves fed restricted amounts of milk has traditionally been discouraged because it could decrease voluntary intake of starter feed because of a potential accumulation of undigested fiber in the rumen (Drackley, 2008). However, some dietary fiber may be necessary for young calves to maintain abrasion in their rumen and avoid abnormal development of the rumen (Greenwood et al., 1997), especially if the starter feed does not have adequate particle size. For example, feeding diets containing fine particles and a high proportion of processed grains has triggered rapid production of acids in the rumen (Laarman et al., 2012), decreased rumen $\mathrm{pH}$ (Laarman and Oba, 2011), and impaired development of rumen epithelium (Greenwood et al., 1997). Drackley (2008) pointed out that if concentrate feeds contain some long particles, such as whole oats, corn, beet pulp, or cottonseed hulls, forage supplementation is not needed, especially if calves are bedded on straw. These starter feeds, typically referred to as texturized, have been reported to increase starter feed intake compared with pelleted starter feeds (Bach 
et al., 2007; Porter et al., 2007) accompanied either with (Porter et al., 2007) or without improvements in growth performance (Bach et al., 2007).

An alternative to avoid abnormal development of the rumen epithelium without using a texturized starter feed could be to offer a pelleted starter feed along with provision of chopped forage. Several authors (Thomas and Hinks, 1982; Khan et al., 2011b; Castells et al., 2012) reported that offering forage in the diet of young calves improved performance and concentrate intake, although in one study (Khan et al., 2011b), growth was mostly due to a confounding effect of gut fill because forage intake was well above $5 \%$ of solid feed intake (it was close to $25 \%$ ). However, to our knowledge no previous study has evaluated the interaction between the physical form of a starter feed and the provision of roughage to young calves. Thus, the current experiments were designed to evaluate growth performance of calves fed starter feeds differing in physical form (texturized or pelleted) with or without chopped straw.

\section{MATERIALS AND METHODS}

\section{Experiment 1}

This study was conducted at the Dairy Education and Research Center of the University of British Columbia in Agassiz (BC). Animals were managed according to the guidelines of the Canadian Council on Animal Care. Thirty-two Holstein calves (23 heifers and 9 bulls) born during summer and fall were separated from their dams and moved to individual pens $(1.7 \times 1.2 \mathrm{~m})$ located in a well-ventilated barn and bedded with sawdust. Calves were fed $4 \mathrm{~L}$ of colostrum within $4 \mathrm{~h}$ of birth and then received $4 \mathrm{~L}$ of pasteurized whole milk twice daily (at 0800 and $1800 \mathrm{~h}$ ) until reaching $7 \mathrm{~d}$ of age. At $7 \mathrm{~d}$ of age (initial $\mathrm{BW}=46.4 \pm 4.91 \mathrm{~kg}$ ), calves were randomly assigned to 1 of 3 dietary treatments: pelleted starter feed and chopped straw (PS), texturized starter feed and chopped straw (TS), and texturized starter feed without straw (TX).

All ingredients in the pelleted starter feed were ground to $3 \mathrm{~mm}$ and then pelleted, whereas in the texturized starter feed corn, barley, and oats were rolled and the rest of the ingredients were also ground to $3 \mathrm{~mm}$ and then pelleted. Pelleted and texturized starter feeds had the same ingredient and nutrient composition (Table 1) and differed only in their physical form. The pelleted starter feed was pelleted at $4 \mathrm{~mm}$ of diameter and 18 $\mathrm{mm}$ in length. The texturized starter feed contained $46.2 \%$ of pellets ( $4 \mathrm{~mm}$ of diameter and $18 \mathrm{~mm}$ long), and the rest was rolled grains (18\% corn, $23 \%$ barley, and $12.8 \%$ oats; Table 1 ). Chopped rye-grass straw was used in the study. The straw was chopped using a TMR mixer (Loewen Horizontal Mixer, Loewen Welding \& Manufacturing Ltd., Matsqui, BC, Canada) at 19,000 rpm for $60 \mathrm{~min}$. The particle-size distribution of straw was determined using the 3-screen Penn State Particle Separator (Kononoff et al., 2003). Chopped straw contained $50 \pm 6.0 \%$ long (>19 mm) particles, $29.5 \pm$ $5.2 \%$ medium $(8-19 \mathrm{~mm})$ particles, $17 \pm 1.3 \%$ short $(1.18-8 \mathrm{~mm})$ particles, and $3.5 \pm 0.5 \%$ fine $(<1.18 \mathrm{~mm})$ particles. Chopped rye-grass straw contained $92 \%$ DM, 8.2\% CP, $72.2 \% \mathrm{NDF}$, and $53 \%$ TDN.

Calves were bottle fed and received $4 \mathrm{~L}$ of pasteurized whole milk twice daily (at 0800 and $1800 \mathrm{~h}$ ) from 7 to $35 \mathrm{~d}$ of age, $2 \mathrm{~L}$ of pasteurized whole milk twice daily from 36 to $42 \mathrm{~d}$ of age, and $2 \mathrm{~L}$ of pasteurized whole milk daily from 43 to $49 \mathrm{~d}$ of age. Calves were weaned at $50 \mathrm{~d}$ of age. Calves had free access to water from a bucket. Starter feed and chopped straw were offered ad libitum in separate buckets until the end of the study when calves reached $63 \mathrm{~d}$ of age.

Starter feed, straw, and milk intakes were recorded daily on an individual basis. Calves were weighed twice weekly about $2 \mathrm{~h}$ from the morning feeding. Heart girth, body barrel, and hip height were measured at the beginning and at the end of the study ( 7 and $63 \mathrm{~d}$ of age). Blood samples (10 mL) were collected at $21,35,49$, and $63 \mathrm{~d}$ of age from the jugular vein to evaluate the evolution of BHBA with age. Rumen liquid was collected 3 to $4 \mathrm{~h}$ after the morning feeding using an oral tube at 35 (preweaning), 49 (weaning), and 63 (postweaning) d of age to measure rumen $\mathrm{pH}$ using a digital $\mathrm{pH}$ meter (pH Testr 30, Eutech Instruments Pte. Ltd., Singapore). Samples of starter feeds, straw, and milk were taken weekly to analyze their nutrient composition.

Samples of whole milk were analyzed for DM (24 $\mathrm{h}$ at $\left.103^{\circ} \mathrm{C}\right)$, ash $\left(4 \mathrm{~h}\right.$ at $\left.550^{\circ} \mathrm{C}\right), \mathrm{N}$ content using the AOAC (1990) method (988.05) adapted for an automatic distiller Kjeldahl (Kjeltec Auto 1030 Analyzer, Tecator, Sweden) with $\mathrm{CuSO}_{4} / \mathrm{Se}$ as a catalyst instead of $\mathrm{CuSO}_{4} / \mathrm{TiO}_{2}$, and ether extract using the AOAC method (920.39) with petroleum ether for distillation instead of diethyl ether (AOAC, 1990). Samples of starter feed and straw were analyzed for DM, ash, and $\mathrm{CP}$ following the same methods described above, plus NDF with sodium sulfite and heat-stable $\alpha$-amylase (Van Soest et al., 1991).

Blood samples were analyzed for BHBA (Precision Xtra blood ketone kit, Abbott Diabetes Care, Madrid, Spain) using the procedures described by Iwersen et al. (2009).

\section{Experiment 2}

This study was conducted at a commercial contract heifer operation (Recria Segle XXI) in Vilanant (Giro- 
Table 1. Ingredient and nutrient composition (DM basis) of the starter feeds

\begin{tabular}{|c|c|c|c|c|}
\hline \multirow[b]{2}{*}{ Item } & \multicolumn{2}{|c|}{ Experiment 1} & \multicolumn{2}{|c|}{ Experiment 2} \\
\hline & Texturized $^{1}$ & Pelleted & Texturized $^{1}$ & Pelleted \\
\hline \multicolumn{5}{|l|}{ Ingredient, \% } \\
\hline Corn, ground & - & 18 & - & 29.0 \\
\hline Corn, rolled & 18.0 & - & - & - \\
\hline Corn, whole & - & - & 29.0 & - \\
\hline Wheat, ground & - & - & 10.0 & 10.0 \\
\hline Soybean meal, ground & 15.0 & 15.0 & 18.5 & 18.5 \\
\hline Barley, ground & - & 23.0 & 9.7 & 9.7 \\
\hline Barley, rolled & 23.0 & - & - & - \\
\hline Oats, ground & - & 12.8 & - & 24.0 \\
\hline Oats, rolled & 12.8 & - & - & - \\
\hline Oats, whole & & & 24.0 & - \\
\hline Wheat middling, ground & 17.5 & 17.5 & 6.0 & 6.0 \\
\hline Distillers dry grains, ground & 7.2 & 7.2 & - & - \\
\hline Molasses & 3.5 & 3.5 & - & - \\
\hline Calcium carbonate & 1.72 & 1.72 & 1.10 & 1.10 \\
\hline Sodium chloride & 0.71 & 0.71 & 0.80 & 0.80 \\
\hline Magnesium oxide & 0.17 & 0.17 & 0.10 & 0.10 \\
\hline Dicalcium phosphate & 0.39 & 0.39 & 0.70 & 0.70 \\
\hline Premix & 0.04 & 0.04 & 0.20 & 0.20 \\
\hline \multicolumn{5}{|l|}{ Nutrient composition } \\
\hline $\mathrm{CP}, \%$ & 19.3 & 19.3 & 18.1 & 18.1 \\
\hline $\mathrm{NDF}, \%$ & 23.2 & 23.2 & 17.8 & 18.2 \\
\hline Ether extract, \% & 3.6 & 3.6 & 4.6 & 4.4 \\
\hline Metabolizable energy, ${ }^{2} \mathrm{Mcal} / \mathrm{kg}$ & 2.88 & 2.88 & 3.00 & 3.00 \\
\hline
\end{tabular}

na, Spain). Animals were managed under the guidelines and approval of the Animal Care Committee of Institut de Recerca i Tecnologia Agroalimentàries. Sixty calves $(40 \pm 4.6 \mathrm{~kg}$ and $8 \pm 3.8 \mathrm{~d}$ old $)$ born during winter were randomly distributed $(\mathrm{n}=20)$ to 3 treatments: pelleted starter feed $(\mathbf{P X})$, the same pelleted starter feed with free choice chopped straw (PS), or a texturized starter feed (TX) with exactly the same ingredient and nutrient composition as the pelleted starter feed (Table 1). Chopped straw was sieved with a 2 -screen Penn State Particle Separator (Lammers et al., 1996) and contained $25.3 \%$ long $(>19 \mathrm{~mm})$ particles, $25.5 \%$ medium $(8-19 \mathrm{~mm})$ particles, and $48.8 \%$ short $(<8$ $\mathrm{mm})$ particles. The pelleted starter feed was pelleted at $4 \mathrm{~mm}$ of diameter and $15 \mathrm{~mm}$ long. The texturized starter feed contained $47 \%$ of pellets ( $4 \mathrm{~mm}$ of diameter and $15 \mathrm{~mm}$ long), and the rest was whole grains $(29 \%$ corn and $24 \%$ oats; Table 1 ).

All calves were managed under the same conditions and housed individually in hutches $(1.10 \times 1.40 \mathrm{~m})$ with an open area $(1 \times 1.25 \mathrm{~m})$ bedded with sawdust. Milk replacer (MR) was offered in buckets, and it was kept to a minimum allowance to encourage solid feed intake and facilitate detection of differences among solid feed treatments. Before arriving to the experimental site, calves were fed $4 \mathrm{~L} / \mathrm{d}$ of a MR diluted at $11 \% \mathrm{DM}$ twice daily. All animals had ad libitum access to fresh water in a bucket. Upon arrival $(8 \pm 3.8 \mathrm{~d}$ old $)$ they received 4
L/d of a MR (23\% CP and 19.5\% fat, Celtilait Sereno, Ploundaniel, France) diluted to achieve 11\% DM. From 14 to $37 \mathrm{~d}$ of age calves received $6 \mathrm{~L} / \mathrm{d}$ of the same MR at the same dilution rate offered in 2 feedings per day, then from 38 to $45 \mathrm{~d}$ of age received $3 \mathrm{~L} / \mathrm{d}$ offered in 2 feedings per day, and from 45 to $52 \mathrm{~d} 1.5 \mathrm{~L} / \mathrm{d}$ once a day. Thus, total MR consumption during the study was $21.7 \mathrm{~kg}$ per calf. Body weight was measured with an electronic scale at the beginning of the study and on a weekly basis thereafter until the age of $52 \mathrm{~d}$ (weaning). Starter feed and straw (if offered) consumption was measured daily until weaning (52 d of age). Furthermore, ruminal fluid was obtained via an oral tube at 1 wk after weaning ( $58 \mathrm{~d}$ of age). Immediately, rumen $\mathrm{pH}$ was measured using a $\mathrm{pH}$ meter (Crison $\mathrm{pH} 25$, Barcelona, Spain). Blood samples from each calf were collected $1 \mathrm{wk}$ after weaning ( $58 \mathrm{~d}$ of age) by venipuncture of the jugular vein into a collection-evacuated tube between 2 and $3 \mathrm{~h}$ after offering the morning starter feed. Blood was kept cold in ice and centrifuged at 1,500 $\times g$ for 15 min at $4^{\circ} \mathrm{C}$ to obtain serum. Serum samples were stored at $-20^{\circ} \mathrm{C}$ until subsequent BHBA analyses.

\section{Statistical Analysis}

For both experiments, performance and intake data were analyzed using a mixed-effects model that accounted for the fixed effects of treatment, time, and 
their 2-way interaction, plus the random effect of calf within treatment, with initial BW and age (for experiment 2 only) considered as covariates. Time of measurement entered the model as repeated measures using the autoregressive order-1 variance-covariance structure in experiment 1 (which yielded the smallest Bayesian information criterion) and the spatial power variance-covariance structure (which was used because time within measurements was unequally spaced and also because it yielded the lowest Bayesian information criterion) in experiment 2. Sex of calves in experiment 1 was initially included in the statistical analysis as a block, but it was later removed because it was not significant for any of the parameters measured. Data for experiment 2 between arrival and $14 \mathrm{~d}$ of age were excluded from the analysis (because not all the animals were enrolled with the same age).

Rumen $\mathrm{pH}$ and serum BHBA concentrations data were analyzed using an ANOVA with treatment as a fixed effect and age at $\mathrm{pH}$ measure as a covariate for rumen $\mathrm{pH}$ analysis. Differences among treatments were assessed using a Tukey's test. Significance was declared at $P<0.05$ and tendencies at $P \leq 0.10$.

\section{RESULTS AND DISCUSSION}

\section{Experiment 1}

Results of growth performance and feed intake are presented in Table 2. Treatments did not differ in starter feed, straw, milk, and total DM intake (milk, starter feed, and straw) before and after weaning. In contrast to the present study, other studies (Franklin et al., 2003; Bach et al., 2007; Porter et al., 2007) reported that calves offered mash, multiparticle, or texturized starter feeds consumed more concentrate than calves fed a pelleted concentrate feed. The PS calves tended $(P=0.06)$ to consume more straw between 28 and 42 d of age than TS calves (Figure 1). Some of the previous studies (Franklin et al., 2003; Porter et al., 2007) evaluating physical form of starter feeds suffered from a confounding between physical form and ingredient and nutrient composition of the starter feeds (which differed with physical forms), and thus changes in intake could not be solely attributed to physical form. Furthermore, better growth rate, early initiation of rumination, more time spent on rumination, greater rumen buffering, and better nutrient digestibility have been reported when course (mash) diets were offered to calves compared with pelleted rations (Franklin et al., 2003; Porter et al., 2007); although again, ingredient and nutrition composition differed between texturized or mash and pellet starter feeds in these 2 studies. Provision of chopped straw with a pelleted starter feed herein pos- sibly alleviated negative effects on rumen buffering and rumination as previously reported by others (Franklin et al., 2003; Bach et al., 2007; Porter et al., 2007) and thus, resulted in comparable voluntary DM consumption to textured starter feeds offered without straw.

The physical form of the starter feed and the availability of straw did not affected ADG and feed intake as a percentage of BW. However, the gain-to-feed ratio was greater $(P<0.05)$ from 28 to $42 \mathrm{~d}$ of age in PS $(0.66 \pm 0.063 \mathrm{~kg}$ of BW $/ \mathrm{kg}$ of DMI) compared with TS $(0.49 \pm 0.063 \mathrm{~kg}$ of $\mathrm{BW} / \mathrm{kg}$ of DMI) and TX $(0.51 \pm$ $0.063 \mathrm{~kg}$ of BW/ $\mathrm{kg}$ of DMI) calves (Figure 2).

Similar to BW gain, structural body measures were also unaffected by the different diets offered to calves. It could be speculated that the increase in feed efficiency was due to an increased gut fill when offering straw to calves; however, at the levels of straw intake herein, gut fill may be negligible. Castells et al. (2013) have recently shown in calves fed pelleted starter feeds that when straw consumption is below $5 \%$ of solid feed intake, gut fill is the same or even lower than when no forage is supplemented. Thus, the increase in feed efficiency when straw was made available to calves with a pelleted starter feed could be linked to an improved digestion efficiency (as discussed later) or, as seen in Porter et al. (2007), when marginal rumen acidosis was eliminated by mash versus pelleted starter feeds.

Calves receiving supplemental straw in the diet, PS and TS treatments, had a greater $(P<0.001)$ rumen $\mathrm{pH}$ compared with those without access to chopped straw (Table 2), suggesting a positive effect of straw supplementation on rumen environment, even when feeding a texturized starter feed. The lower rumen $\mathrm{pH}$ in TX could be partially attributed to the presence of processed corn and oats in the formulation of this starter feed. Nevertheless, increased rumen $\mathrm{pH}$ when forage is included in the diet has been previously reported in the literature (Thomas and Hinks, 1982; Khan et al., 2011b; Terré et al., 2013). However, the greater feed efficiency of PS over TS calves observed herein could not only be attributed to increased rumen $\mathrm{pH}$, but could also possibly be attributed to an increased digestibility of nutrients when provided as pellets (NRC, 2001). Starch availability, and therefore digestibility, is typically greatest in steam-flaked grains, followed by finely ground, then dry-rolled grains (Offner et al., 2003). Barley, corn, and oats were rolled in TS and TX but ground in PS, and thus it is likely that digestibility was greater in PS than in TS.

Blood BHBA increased with calf age $(P<0.001)$, but treatments did not differ in blood BHBA. The increase in blood BHBA with age has been previously described in the literature (Quigley et al., 1992; Khan et al., 2011b). This increase indicates a shift in the source 
Table 2. Growth, feed intake, rumen $\mathrm{pH}$, blood BHBA concentrations, and structural body measures of calves fed a texturized starter feed with (TS) or without (TX) straw, or a pelleted starter feed plus straw (PS) from 7 to $63 \mathrm{~d}$ of age (experiment 1)

\begin{tabular}{|c|c|c|c|c|c|c|}
\hline \multirow[b]{2}{*}{ Item } & \multicolumn{3}{|c|}{ Treatment } & \multirow[b]{2}{*}{ SEM } & \multicolumn{2}{|c|}{$P$-value ${ }^{1}$} \\
\hline & PS & $\mathrm{TX}$ & TS & & $\mathrm{T}$ & $\mathrm{T} \times \mathrm{t}$ \\
\hline Initial BW, kg & 46.5 & 46.2 & 46.4 & 1.55 & 0.99 & - \\
\hline Final BW, kg & 86.5 & 87.5 & 83.4 & 3.48 & 0.76 & - \\
\hline \multicolumn{7}{|c|}{ Preweaning, 7 to $49 \mathrm{~d}$ of age } \\
\hline \multicolumn{7}{|l|}{ Intake } \\
\hline Milk, $\mathrm{kg}$ of DM/d & 0.83 & 0.81 & 0.83 & 0.010 & 0.29 & 0.55 \\
\hline Starter, $\mathrm{kg}$ of DM/d & 0.32 & 0.28 & 0.26 & 0.049 & 0.71 & 0.81 \\
\hline Straw, $\mathrm{kg}$ of $\mathrm{DM} / \mathrm{d}$ & 0.03 & - & 0.05 & 0.007 & 0.13 & 0.06 \\
\hline TDMI, ${ }^{2} \mathrm{~kg}$ of DM/d & 1.18 & 1.09 & 1.13 & 0.055 & 0.53 & 0.80 \\
\hline DMI, $\%$ of $\mathrm{BW}$ & 1.99 & 1.87 & 1.95 & 0.102 & 0.73 & 0.90 \\
\hline Gain-to-feed ratio ${ }^{3}$ & 0.60 & 0.54 & 0.53 & 0.033 & 0.27 & $<0.05$ \\
\hline \multicolumn{7}{|c|}{ Postweaning, 50 to $63 \mathrm{~d}$ of age } \\
\hline $\mathrm{ADG}, \mathrm{kg} / \mathrm{d}$ & 0.89 & 0.97 & 0.92 & 0.078 & 0.75 & 0.41 \\
\hline \multicolumn{7}{|l|}{ Intake } \\
\hline Starter, $\mathrm{kg}$ of $\mathrm{DM} / \mathrm{d}$ & 1.97 & 1.93 & 1.91 & 0.135 & 0.97 & 0.29 \\
\hline Straw, $\mathrm{kg}$ of $\mathrm{DM} / \mathrm{d}$ & 0.11 & - & 0.15 & 0.027 & 0.37 & 0.49 \\
\hline TDMI, $\mathrm{kg}$ of DM/d & 2.09 & 1.94 & 2.07 & 0.129 & 0.69 & 0.39 \\
\hline DMI, $\%$ of BW & 2.66 & 2.42 & 2.68 & 0.177 & 0.51 & 0.29 \\
\hline Gain-to-feed ratio ${ }^{3}$ & 0.42 & 0.50 & 0.47 & 0.040 & 0.39 & 0.69 \\
\hline Ruminal pH & $5.9^{\mathrm{a}}$ & $5.4^{\mathrm{b}}$ & $5.8^{\mathrm{a}}$ & 0.07 & $<0.001$ & 0.85 \\
\hline Blood BHBA, mmol/L & 0.15 & 0.14 & 0.16 & 0.034 & 0.96 & 0.88 \\
\hline \multicolumn{7}{|c|}{ Structural body measures, $\mathrm{cm}$} \\
\hline Hip height, $7 \mathrm{~d}$ & 82.4 & 83.5 & 84.1 & 1.20 & 0.88 & 0.14 \\
\hline Hip height, 63 d & 98.5 & 98.7 & 97.1 & 1.16 & & \\
\hline Hearth girth, $7 \mathrm{~d}$ & 85.0 & 85.2 & 85.4 & 1.48 & 0.96 & 0.99 \\
\hline Hearth girth, $63 \mathrm{~d}$ & 103.7 & 104.1 & 104.2 & 1.41 & & \\
\hline Body barrel, $7 \mathrm{~d}$ & 86.9 & 86.8 & 85.7 & 2.11 & 0.86 & 0.53 \\
\hline Body barrel, $63 \mathrm{~d}$ & 118.6 & 117.7 & 121.1 & 2.00 & & \\
\hline
\end{tabular}

${ }^{\mathrm{a}, \mathrm{b}}$ Means within a row with uncommon superscripts differ $(P<0.05)$.

${ }^{1} \mathrm{~T}=$ treatment effect; $\mathrm{T} \times \mathrm{t}=$ interaction between treatment and time.

${ }^{2} \mathrm{TDMI}=$ total DMI (milk replacer, starter feed, and straw).

${ }^{3} \mathrm{~kg}$ of BW gain $/ \mathrm{kg}$ of TDMI.

of energy from liquid to solid diets and an increased consumption of fermentable carbohydrates with age. Similar to the present study, the inclusion of forage in the diet of young calves and physical form of the starter feed has been reported to have no effect in blood BHBA concentrations (Greenwood et al., 1997; Coverdale et al., 2004; Khan et al., 2011b).

It can be concluded that calves fed high milk allowances along with a texturized starter feed with or without straw supplementation had similar growth performance compared with the same nutrients and ingredients presented in a pelleted starter feed offered with chopped straw. However, provision of texturized starter feed similar to the one fed herein without straw could decrease rumen $\mathrm{pH}$.

\section{Experiment 2}

Calves had similar BW at the beginning of the study (Table 3); however, at the end of the preweaning period (52 d of age), BW was greater in PS than in PX and
TX treatments $(P<0.05)$. Calves in PX treatment grew faster $(P<0.05)$ at the beginning of the study; however, ADG was greater with PS compared with PX and TX at 35 and $42 \mathrm{~d}$ of age. Furthermore, TX had greater ADG at $56 \mathrm{~d}$ of age than PX calves (Figure 3). Although starter feed intake was similar in the 3 treatments, total DMI was greater $(P<0.05)$ in PS than in PX and TX, mainly because of a greater $(P<0.05)$ total DMI in d 49 and 56 of age. Furthermore, calves fed TX had greater total DMI than PX calves at $52 \mathrm{~d}$ of age (Figure 4). Total DMI as a percentage of BW was also greatest in PS calves (Table 3). Increased solid feed intake when providing chopped straw to calves fed pelleted diets has been previously reported (Castells et al., 2012). There have been some concerns in the literature (Kertz, 2007) about the potential confounding effects on growth when offering forage to young calves. These concerns are mainly based on early studies with relatively high levels of forage inclusion in the diet. For instance, Stobo et al. (1966) showed that if concentrate intake was restricted from 2.27 to $0.45 \mathrm{~kg} / \mathrm{d}$ and calves 


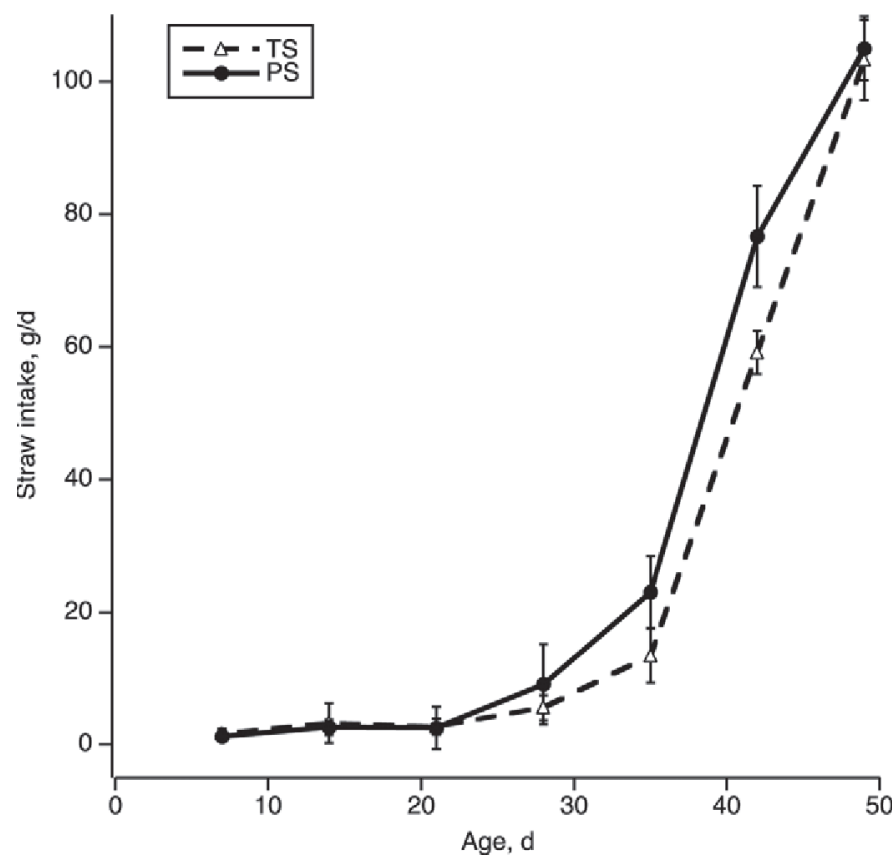

Figure 1. Evolution (from 7 to $49 \mathrm{~d}$ of age) of straw intake in calves fed a texturized starter feed plus chopped straw (TS) or fed a pelleted starter feed plus chopped straw (PS; experiment 1). Error bars indicate SEM for each time point.

were forced to rely on forage as the main source of nutrients, gut fill increased from 14.7 to $23.3 \%$ of live BW (mainly because forage did not foster much BW gain). Nevertheless, in that study, when forage intake was 3.8 or $14.8 \%$ of total feed intake, gut fill at $84 \mathrm{~d}$ of age did not differ much (14.7 vs. $15.2 \%$ ). More recently, Castells et al. (2013) showed that when calves consumed $4.7 \%$ of total solid feed intake in the form of oats hay, gut fill was actually lesser than when calves consumed a pelleted starter alone (mainly due to increased total solid feed intake and growth performance). The results from Castells et al. (2013) are also consistent with early reports conducted in older calves (Strozinski and Chandler, 1971) that showed that when forage intake was below $5 \%$ of total DMI, gut fill was negligible (about $0.63 \%$ increase in gut fill as they reported an increase in gut fill of $0.13 \%$ for every percentage unit increase in the proportion of hay in the diet). In the current study, even if we would assume that all straw consumed stayed in the rumen (an unlikely assumption) making a net contribution to gut fill, the apparent increase in $\mathrm{BW}$ due to gut fill would have been of $1.35 \mathrm{~kg}$, a value still inferior to the difference observed in BW between PS and TX or PS and PX. On the other hand, Fokkink et al. (2011) compared body growth and gut fill of calves consuming a texturized starter feed with a pelleted starter feed with free access to straw and reported greater proportional weight of stomach, intestine, and

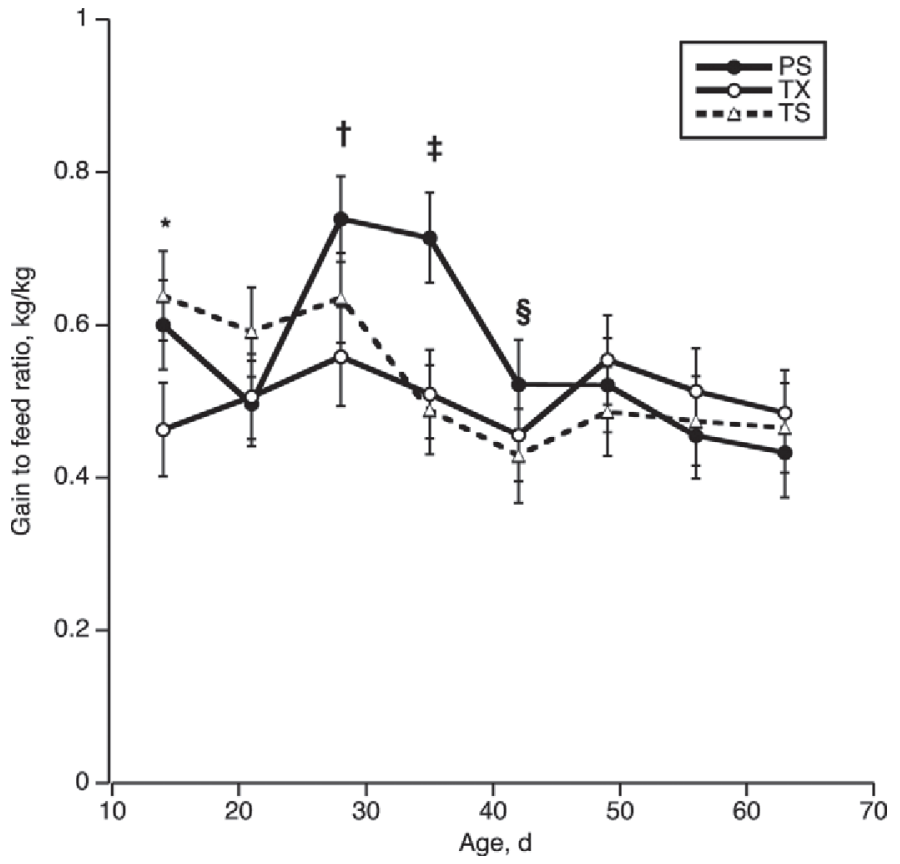

Figure 2. Evolution of feed-to-gain ratio (ADG/DMI) throughout ages (from 7 to $63 \mathrm{~d}$ ) as affected by treatment (PS $=$ pelleted starter feed plus chopped straw supplementation; TX = texturized starter feed with no straw supplementation; TS = texturized starter feed with chopped straw supplementation; experiment 1$). *$ Differences $(P<0.05)$ between TX and PS and TX treatments; $\dagger$ differences $(P<$ $0.05)$ between PS and TX treatments; $\ddagger$ differences $(P<0.05)$ between PS and TX and TS treatments; and §differences $(P<0.05)$ between PS and TS treatments. Error bars indicate SEM for each time point.

digesta in calves consuming a pelleted starter feed than calves consuming a texturized starter feed. Furthermore, in that study, digesta content (gut fill) tended to be lower in calves consuming a pelleted starter feed (5.8 $\mathrm{kg}$ ) than that in those consuming a texturized starter feed $(7.0 \mathrm{~kg})$ despite the fact that straw intake was around $1 \%$ of starter feed intake. However, the starter feeds differed in ingredient and also nutrient composition. The pelleted starter feed provided 0.16 Mcal of ME less per kilogram, which resulted in poorer growth of calves and, thus, proportionally greater weight of the gastrointestinal tract. In veal calves, consuming limited amounts of solid feed ( $~ 800 \mathrm{~g} / \mathrm{d}$ at 10 wk of age), Suárez et al. (2007) reported no differences in gut fill between calves offered starter feed alone or calves offered either corn silage, straw, or different combination of the latter at different amounts.

In contrast to experiment 1 , where no differences in growth performance were observed, supplementation of straw with a pelleted starter feed improved the BW of calves within the preweaning period. This could be attributed to the different milk allowance between both experiments (more than twice the milk allowance in experiment 1 than in experiment 2) that could influ- 


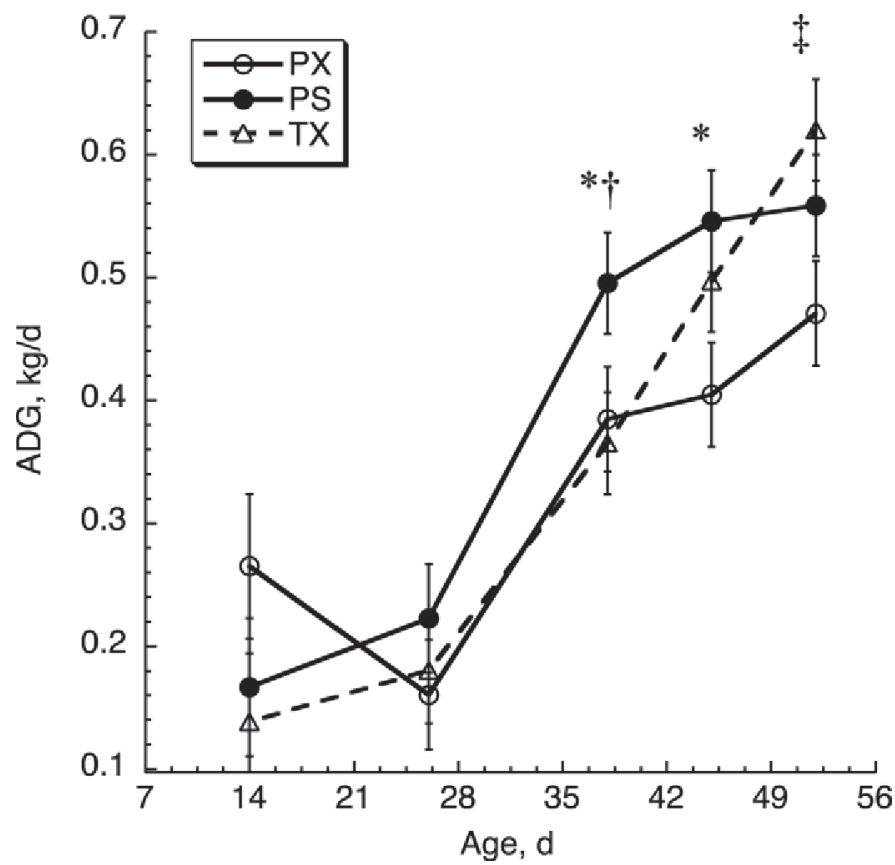

Figure 3. Evolution (from 8 to $52 \mathrm{~d}$ of age) of ADG throughout the preweaning period as affected by treatment $(\mathrm{PX}=$ pelleted starter feed with no straw supplementation; PS = pelleted starter feed plus chopped straw supplementation; TX $=$ texturized starter feed with no straw supplementation; experiment 2$)$. ${ }^{*}$ Differences $(P<0.05)$ in ADG between PX and PS treatments; †differences $(P<0.05)$ in ADG between PS and TX treatments; and $\ddagger$ differences $(P<0.05)$ in ADG between PX and TX treatments. Error bars indicate SEM for each time point.

ence solid feed intake during the preweaning period. Solid feed intake was $>50 \%$ of the total DMI (solid plus liquid feed) in experiment 2, whereas it was $<30 \%$

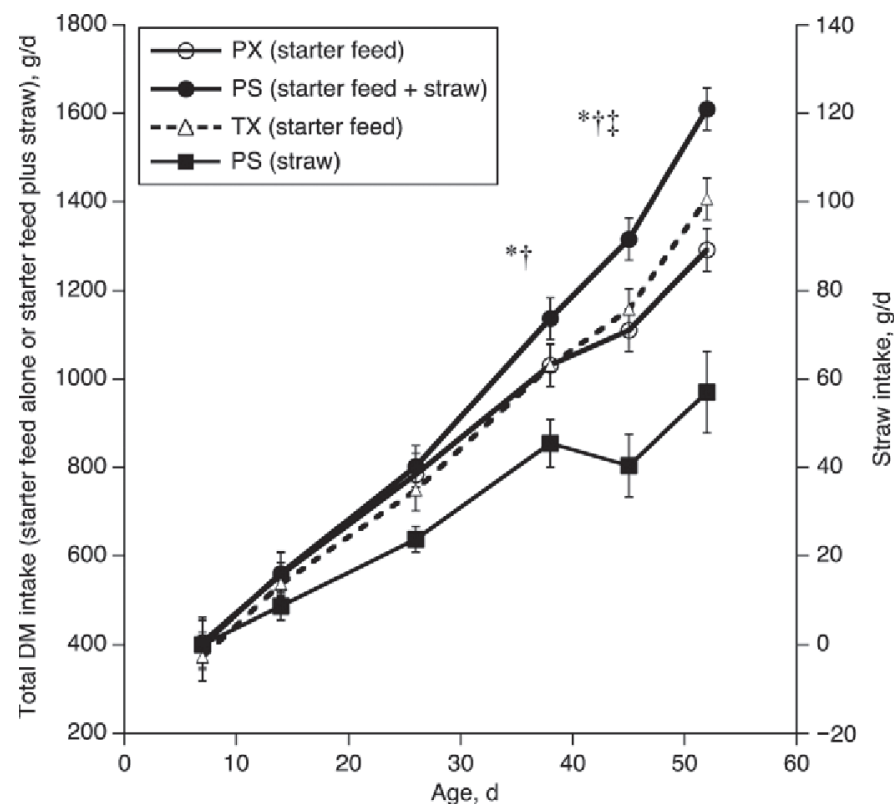

Figure 4. Evolution (from 8 to $52 \mathrm{~d}$ of age) of total DMI (left axis) and straw intake (right axis) throughout the preweaning period as affected by treatment $(\mathrm{PX}=$ pelleted starter feed with no straw supplementation; PS = pelleted starter feed plus chopped straw supplementation; $\mathrm{TX}=$ texturized starter feed with no straw supplementation; experiment 2$).{ }^{*}$ Differences $(P<0.05)$ in intake between PX and PS treatments; †differences $(P<0.05)$ in total DMI between PS and TX treatments, and $\ddagger$ differences $(P<0.05)$ in total DMI between PX and TX treatments. Error bars indicate SEM for each time point.

in experiment 1 . This indicates that calves in experiment 2 were more dependent on solid feed compared with those in experiment 1 , and therefore, a potential effect of solid feed treatments was more evident dur-

Table 3. Growth and feed intake (DM basis) of calves fed a pellet (PX), a pellet plus straw (PS), or a texturized concentrate (TX) from $8 \mathrm{~d}$ of life until weaning (52 d of age), and BW, serum BHBA, and rumen $\mathrm{pH}$ at $58 \mathrm{~d}$ of age (experiment 2)

\begin{tabular}{|c|c|c|c|c|c|c|c|}
\hline \multirow[b]{2}{*}{ Item } & \multicolumn{3}{|c|}{ Treatment } & \multirow[b]{2}{*}{ SEM } & \multicolumn{3}{|c|}{$P$-value ${ }^{1}$} \\
\hline & $\mathrm{PX}$ & PS & $\mathrm{TX}$ & & $\mathrm{T}$ & $\mathrm{t}$ & $\mathrm{T} \times \mathrm{t}$ \\
\hline Initial BW, kg & 40.2 & 39.9 & 40.2 & 1.08 & 0.98 & - & - \\
\hline $\mathrm{BW}$ at $52 \mathrm{~d}, \mathrm{~kg}$ & 54.6 & 57.4 & 55.1 & 0.89 & 0.30 & $<0.001$ & 0.014 \\
\hline $\mathrm{ADG}, \mathrm{kg} / \mathrm{d}$ & 0.34 & 0.40 & 0.36 & 0.030 & 0.35 & $<0.001$ & 0.024 \\
\hline \multicolumn{8}{|l|}{ Feed intake, $\mathrm{kg}$ of $\mathrm{DM} / \mathrm{d}$} \\
\hline Milk replacer & 0.44 & 0.44 & 0.44 & 0.005 & 0.76 & $<0.001$ & 0.98 \\
\hline Starter feed & 0.51 & 0.60 & 0.53 & 0.038 & 0.26 & $<0.001$ & 0.11 \\
\hline Straw & - & 0.026 & - & - & - & - & - \\
\hline $\mathrm{TDMI}^{2}$ & $0.95^{\mathrm{b}}$ & $1.08^{\mathrm{a}}$ & $0.97^{\mathrm{b}}$ & 0.039 & 0.04 & $<0.001$ & 0.015 \\
\hline DMI, $\%$ of BW & $1.95^{\mathrm{b}}$ & $2.27^{\mathrm{a}}$ & $2.01^{\mathrm{b}}$ & 0.058 & 0.039 & $<0.001$ & 0.50 \\
\hline Gain-to-feed ratio ${ }^{3}$ & 0.36 & 0.37 & 0.37 & 0.021 & 0.95 & $<0.001$ & 0.08 \\
\hline Serum BHBA, mmol/L & 0.2 & 0.29 & 0.30 & 0.028 & 0.82 & - & - \\
\hline Rumen pH & $5.07^{\mathrm{b}}$ & $5.32^{\mathrm{a}}$ & $5.44^{\mathrm{a}}$ & 0.082 & 0.008 & - & - \\
\hline
\end{tabular}

${ }^{\mathrm{a}, \mathrm{b}}$ Means within a row with uncommon superscripts differ $(P<0.05)$.

${ }^{1} \mathrm{~T}=$ treatment effect; $\mathrm{t}=$ time effect; $\mathrm{T} \times \mathrm{t}=$ interaction between treatment and time.

${ }^{2} \mathrm{TDMI}=$ total DMI (milk replacer, starter feed, and straw).

${ }^{3} \mathrm{~kg}$ of BW gain $/ \mathrm{kg}$ of TDMI. 
ing the preweaning period in experiment 2. Nevertheless, solid feed intake in experiment 2 was lower than reported elsewhere (Hengst et al., 2012; Kmicikewycz et al., 2013), although similar to other studies offering restricted milk allowances (Ballou, 2012; Obeidat et al., 2013).

In experiment 2 , at $52 \mathrm{~d}$ of age calves offered TX had greater total DMI and ADG than PX calves. Previous studies have also reported similar observations (Franklin et al., 2003; Bach et al., 2007; Porter et al., 2007) when comparing texturized or mash versus pellet concentrates without forage provision, although as discussed above, in some of these studies the ingredient and nutrient composition of the starter feeds with different physical forms were not equal (Franklin et al., 2003; Porter et al., 2007). However, Bateman et al. (2009) compared 2 starter feeds with identical ingredient and nutrient composition but different physical form. In one trial they compared texturized versus pellet and found no differences in intake or growth (calves were bedded with straw). In another trial, however, they compared a texturized starter feed with a mixture of a texturized starter and a mash starter feed and reported greater DMI and growth in calves consuming the texturized starter. Authors attributed the differences to the high proportion of fine particles $(96 \%$ of particles were $<1,180 \mu \mathrm{m})$ in the half-texturized, half-mash starter feed compared with the texturized starter feed $(19 \%$ of particles $<1,180 \mu \mathrm{m})$. In the current study, despite the greater DMI in TX than PX calves, gain-to-feed ratio did not differ among the 3 diets. Calves fed PS had greater ADG and total DMI from $38 \mathrm{~d}$ of age to weaning than calves fed PX. Similar to present results, Thomas and Hinks (1982) and Castells et al. (2012) reported that the provision of a forage source to young calves fed a pelleted starter feed resulted in improved growth rate and total DMI, but Quigley et al. (1985) reported greater DMI in calves fed a pelleted starter without forage supplementation compared with calves fed a ground or mash starter feed supplemented with forage (a mixture of grass and alfalfa hay) when calves were weaned at 4 wk of age but no differences when calves were weaned at $8 \mathrm{wk}$ of age.

Rumen $\mathrm{pH}$ was greater in PS and TX compared with PX treatments (Table 3). In contrast to experiment 2, TX and PS treatments in experiment 1 had different rumen $\mathrm{pH}$. The main differences in the texturized starter feeds between both experiments were the level of NDF (23.2 vs. 17.1\%, in experiment 1 and 2, respectively) and the physical form of corn (rolled vs. whole, in experiment 1 and 2, respectively). However, a direct comparison between 2 experiments is not logical because of the differences in ingredient composition and level of starter feed intake. Previously, Terré et al.
(2013) reported similar rumen $\mathrm{pH}$ in calves fed either low- $(18.2 \%)$ or high-NDF $(26.7 \%)$ starter diets. However, Lesmeister and Heinrichs (2004) reported that a texturized starter feed containing whole corn resulted in greater rumen $\mathrm{pH}$ in calves compared with those contained dried-rolled corn, roasted-rolled corn, or steamflaked corn, which would be consistent with whole corn requiring more chewing than the other processed forms of corn. The NDF content of starters in that study was also similar to the $17 \%$ in TX of experiment 2 .

In the current study, under a low MR allowance during the preweaning period, provision of a pelleted starter feed supplemented with straw promoted solid feed intake, compared with those calves that received the same starter feed either in pelleted or texturized form without straw. Furthermore, a texturized starter feed including whole corn had similar benefits on rumen $\mathrm{pH}$ as a pelleted starter feed supplemented with straw.

\section{ACKNOWLEDGMENTS}

A special thanks is extended to $\mathrm{Al} \mathrm{Kertz} \mathrm{(ANDHIL}$ LLC, St. Louis, MO) for providing support in the formulation of the pelleted starter feed used in experiment 2 and for critical discussions and contributions to this manuscript. The assistance from Lori Vickers from University of British Columbia and Matthieu Lacroix from LaSalle Polytechnic Institute (Beauvais, France) is greatly appreciated. We also thank Recria Segle XXI for allowing the study to be performed in their facilities. The Animal Welfare Program is funded by Canada's Natural Sciences and Engineering Research Council Industrial Research Chair Program with industry contributions from the Dairy Farmers of Canada (Ottawa, ON, Canada), Westgen Endowment Fund (Milner, BC, Canada), Zoetis (Kirkland, QC, Canada), BC Cattle Industry Development Fund (Kamloops, BC, Canada), the BC Dairy Education and Research Association (Abbotsford, BC, Canada), and Alberta Milk (Edmonton, AB, Canada). Financial support for Alex Bach from Ministerio de Educación of the Spanish Government through the program Salvador de Madariaga expedient number PR2010-0081 is acknowledged.

\section{REFERENCES}

AOAC. 1990. Official Methods of Analysis. 15th ed. Association of Official Analytical Chemists, Arlington, VA.

Bach, A., A. Giménez, J. L. Juaristi, and J. Ahedo. 2007. Effects of physical form of a starter for dairy replacement calves on feed intake and performance. J. Dairy Sci. 90:3028-3033.

Ballou, M. A. 2012. Immune responses of Holstein and Jersey calves during the preweaning and immediate postweaned periods when fed varying planes of milk replacer. J. Dairy Sci. 95:7319-7330.

Bateman, H. G., II, T. M. Hill, J. M. Aldrich, and R. L. Schlotterbeck. 2009. Effects of corn processing, particle size, and diet form on performance of calves in bedded pens. J. Dairy Sci. 92:782-789. 
Castells, Ll., A. Bach, G. Araujo, C. Montoro, and M. Terré. 2012. Effect of different forage sources on performance and feeding behavior of Holstein calves. J. Dairy Sci. 95:286-293.

Castells, Ll., A. Bach, A. Arís, and M. Terré. 2013. Effects of forage provision to young calves on rumen fermentation and development of the gastrointestinal tract. J. Dairy Sci. 96:5226-5236.

Coverdale, J. A., H. D. Tyler, J. D. Quigley III, and J. A. Brumm. 2004. Effect of various levels of forage and form of diet on rumen development and growth in calves. J. Dairy Sci. 87:2554-2562.

Drackley, J. K. 2008. Calf nutrition from birth to breeding. Vet. Clin. North Am. Food Anim. Pract. 24:55-86.

Fokkink, W. B., T. M. Hill, H. G. Bateman II, J. M. Aldrich, R. L. Schlotterbeck, and A. F. Kertz. 2011. Case study: Effect of highand low-cereal-grain starters on straw intake and rumen development of neonatal Holstein calves. Prof. Anim. Sci. 27:357-364.

Franklin, S. T., D. M. Amaral-Philips, J. A. Jackson, and A. A. Campbell. 2003. Health and performance of Holstein calves that suckled or were hand-fed colostrum and were fed one of three physical forms of starter. J. Dairy Sci. 86:2145-2153.

Greenwood, R. H., J. L. Morrill, E. C. Titgemeyer, and G. A. Kennedy. 1997. A new method of measuring diet abrasion and its effect on the development of the forestomach. J. Dairy Sci. 80:2534-2541.

Hengst, B. A., L. M. Nemec, R. R. Rastani, and T. F. Gressley. 2012. Effect of conventional and intensified milk replacer feeding programs on performance, vaccination response, and neutrophil mRNA levels of Holstein calves. J. Dairy Sci. 95:5182-5193.

Iwersen, M., U. Falkenberg, R. Voigtsberger, D. Forderung, and W. Heuwieser. 2009. Evaluation of an electronic cowside test to detect subclinical ketosis in dairy cows. J. Dairy Sci. 92:2618-2624.

Kertz, A. F. 2007. Letter to the editor: Pelleted calf starter with straw access can confound results: A comment on Bach et al. (2007). J. Dairy Sci. 90:4924.

Khan, M. A., D. M. Weary, and M. A. G. von Keyserlingk. 2011a. Invited review: Effects of milk ration on solid feed intake, weaning and performance in dairy heifers. J. Dairy Sci. 94:1071-1081.

Khan, M. A., D. M. Weary, and M. A. G. von Keyserlingk. 2011b. Hay intake improves performance and rumen development of calves fed higher quantities of milk. J. Dairy Sci. 94:3547-3553.

Kmicikewycz, A. D., D. N. L. da Silva, J. G. Linn, and N. B. Litherland. 2013. Effects of milk replacer program fed 2 or 4 times daily on nutrient intake and calf growth. J. Dairy Sci. 96:1125-1134.

Kononoff, P. J., A. J. Heinrichs, and D. R. Buckmaster. 2003. Modification of the Penn State forage and total mixed ration particle separator and the effects of moisture content on its measurements. J. Dairy Sci. 86:1858-1863.

Laarman, A. H., and M. Oba. 2011. Short communication: Effect of calf starter on rumen $\mathrm{pH}$ of Holstein dairy calves at weaning. J. Dairy Sci. 94:5661-5664.
Laarman, A. H., A. L. Ruiz-Sanchez, T. Sugino, L. L. Guan, and M. Oba. 2012. Effects of feeding a calf starter on molecular adaptations in the ruminal epithelium and liver of Holstein dairy calves. J. Dairy Sci. 95:2585-2594.

Lammers, B. P., D. R. Buckmaster, and A. J. Heinrichs. 1996. A simplified method for the analysis of particle sizes of forage and total mixed rations. J. Dairy Sci. 79:922-928.

Lesmeister, K. E., and A. J. Heinrichs. 2004. Effects of corn processing on growth characteristics, rumen development, and rumen parameters in neonatal dairy calves. J. Dairy Sci. 87:3439-3450.

NRC. 2001. Nutrient Requirements of Dairy Cattle. 7th rev. ed. Natl. Acad. Sci., Washington, DC.

Obeidat, B. S., C. J. Cobb, M. D. Sellers, A. R. Pepper-Yowell, T. J. Earleywine, and M. A. Ballou. 2013. Plane of nutrition during the preweaning period but not the grower phase influences the neutrophil activity of Holstein calves. J. Dairy Sci. 96:7155-7166.

Offner, A., A. Bach, and D. Sauvant. 2003. Quantitative review of in situ starch degradation in the rumen. Anim. Feed Sci. Technol. 106:81-93.

Porter, J. C., R. G. Warner, and A. F. Kertz. 2007. Effect of fiber level and physical form of starter on growth and development of dairy calves fed no forage. Prof. Anim. Sci. 23:395-400.

Quiqley, J. D., C. G. Schwab, and W. E. Hylton. 1985. Development of rumen function in calves: Nature of protein reaching the abomasum. J. Dairy Sci. 68:694-702.

Quigley, J. D., III, T. M. Steen, and S. I. Boehms. 1992. Postprandial changes of selected blood and ruminal metabolites in ruminating calves fed diets with or without hay. J. Dairy Sci. 75:228-235.

Stobo, I. J. F., J. H. B. Roy, and H. J. Gaston. 1966. Rumen development in the calf. Br. J. Nutr. 20:189-215.

Strozinski, L. L., and P. T. Chandler. 1971. Effects of dietary fiber and acid-detergent lignin on body fill of ruminating calves. J. Dairy Sci. 54:1491-1495.

Suárez, B. J., C. G. Van Reenen, N. Stockhofe, J. Dijkstra, and W. J. J. Gerrits. 2007. Effect of roughage source and roughage to concentrate ratio on animal performance and rumen development in veal calves. J. Dairy Sci. 90:2390-2403.

Terré, M., E. Pedrals, A. Dalmau, and A. Bach. 2013. What do preweaned and weaned calves need in the diet: A high fiber content or a forage source? J. Dairy Sci. 96:5217-5225.

Thomas, D. B., and C. E. Hinks. 1982. The effect of changing the physical form of roughage on the performance of the early-weaned calf. Anim. Prod. 35:375-384.

Van Soest, P. J., J. B. Robertson, and B. A. Lewis. 1991. Methods for dietary fiber, neutral detergent fiber, an nonstarch polysaccharides in relation to animal nutrition. J. Dairy Sci. 74:3583-3597. 